\title{
Percepção de estudantes de enfermagem sobre o portfólio como estratégia de ensino, aprendizagem e avaliação
}

Perception of nursing students about portfolio as a teaching strategy, learning and assessment

Percepción de los estudiantes de enfermería sobre el portafolio reflexivo como una estrategia de enseñanza, aprendizaje y evaluación

Ana Paula da Silva LEMOS ${ }^{(1)}$ Rosângela Minardi Mitre COTTA ${ }^{(2)}$

Glauce Dias da COSTA ${ }^{(3)}$

Erica Toledo de MENDONÇA ${ }^{(4)}$

Emily de Souza FERREIRA ${ }^{(1)}$

(1) Universidade Federal de Viçosa - UFV, Viçosa, MG, Brasil.

(2) Universidade Federal de Viçosa - UFV, Programa de Inovação em Docência Universitária, Viçosa, MG, Brasil.

(3) Universidade Federal de Viçosa - UFV, Departamento de Nutrição e Saúde, Viçosa, MG, Brasil.

(4) Universidade Federal de Viçosa - UFV, Departamento de Medicina e Enfermagem, Viçosa, MG, Brasil.

Recebido: 26 jan 2017

Revisado: 23 fev 2017

Aceito: 14 mar 2017

Autor de

correspondência:

Ana Paula da Silva Lemos anapaula.ufv@outlook.com

Conflito de interesses: Os autores declaram não haver nenhum interesse profissional ou pessoal que possa gerar conflito de interesses em relação a este manuscrito.

\section{Resumo}

O objetivo deste trabalho foi analisar a percepção dos estudantes do curso de Enfermagem de uma universidade pública sobre o processo de construção do portfólio. A abordagem qualitativa foi a opção metodológica utilizada e os dados foram coletados por meio de entrevistas com os estudantes e análise documental dos portfólios. A análise dos dados foi realizada a partir da técnica de Análise de Conteúdo. Os principais achados deste estudo sobre o portfólio foram: potente indutor e potencializador do trabalho em equipe; estratégia que permite (re)significar e aprofundar o conhecimento; recurso de consolidação do aprendizado; estratégia de ensino, aprendizagem e avaliação formativa, crítica, reflexiva, criativa, dialética que estimula e valoriza a participação do aluno; promotor do crescimento enquanto estudante, cidadão e futuro profissional; estimula a reflexão e participação ativa nos acontecimentos do mundo real, principalmente aqueles ligados à saúde. Ademais, uma maneira de ampliar, (re)pensar e inovar o ensino de graduação.

Descritores: Enfermagem; ensino; aprendizagem; avaliação; inovação. 


\begin{abstract}
This study aimed to analyze the perception of students from the nursing undergraduate program at a public university about the construction process of portfolio. The qualitative research approach was the methodological choice; the data were collected through interviews with students and documentary analysis of portfolios. Data analysis was performed using the content analysis technique. The main findings of this study, from the perspective of students on the portfolio, were: potent inducer and enhancer of teamwork; strategy that allows to define and deepen the content; the consolidation of learning resource; teaching strategy, learning and formative assessment, critical , reflective, creative and dialectical, whose encourages and enrich the student participation, promotes student, citizen and professional growth for the future; inspire reflection and active participation in real-world events, especially those related to health. Finally, reflective portfolio is a method to broaden and the innovate the undergraduate.
\end{abstract}

Keywords: Nursing; teaching; learning; evaluation; innovation.

\begin{abstract}
Resumen
El objetivo de este estudio fue analizar la percepción de los alumnos del curso de Enfermería de la Universidad pública en el proceso de construcción del portafolio reflexivo en la asignatura de Políticas de Salud. El enfoque cualitativo fue la opción metodológica, y se recogieron los datos por medio de entrevistas con los estudiantes y análisis documental de las carteras. El análisis de datos se realizó a partir de la técnica de análisis de contenido. Las principales conclusiones de este estudio, desde la perspectiva de los estudiantes en la cartera fueron potente inductor y potenciador del trabajo en equipo; estrategia que permite (re)definir y profundizar en el conocimiento; la consolidación de recursos para el aprendizaje; la enseñanza de la estrategia, el aprendizaje y la evaluación formativa, crítico, reflexivo, creativo, dialéctica que fomenta y valora la participación de los estudiantes, promotor del crecimiento como estudiante, ciudadano y futuro profesional; anima a la reflexión y la participación activa en los acontecimientos del mundo real, especialmente los relacionados con la salud. Por último, una manera de extender (re)pensar e innovar la educación de pregrado.
\end{abstract}

Palabras-claves: Enfermería, Portafolio de reflexión, métodos activos

\title{
Introdução
}

As Diretrizes Curriculares Nacionais - DCN do curso de graduação em Enfermagem apontam para a necessidade de que se produzam mudanças na educação universitária visando a: "Uma formação generalista, humanista, crítica e reflexiva. Profissional qualificado para o exercício da Enfermagem com base no rigor científico e intelectual e pautado em princípios éticos. Capacitado a atuar com senso de responsabilidade social e compromisso com a cidadania, como promotor de saúde integral do ser humano" ${ }^{1, \text { p. } 1}$

Nessa linha, o novo paradigma de ensino recomendado DCN dos cursos da área de saúde enfatiza a necessidade de mudança do processo de ensino-aprendizagem, em que os estudantes assumem um papel de protagonista nesse processo. ${ }^{2}$ 
Destarte, visando ao alcance da formação crítica e reflexiva, tem sido discutido o uso de métodos ativos de ensino, aprendizagem e avaliação de forma a incentivar a participação ativa dos estudantes, tanto em sua própria formação como na construção de uma lógica de cuidado ampliada e integral, em conformidade com os princípios e diretrizes do Sistema Único de Saúde - SUS. ${ }^{3,4}$

Essa mudança de foco no processo de educação tem como objetivo central a mudança do papel dos estudantes (futuros profissionais), estimulando a autonomia, criatividade e corresponsabilidade por sua própria formação e dos colegas, desenvolvendo processos críticos e reflexivos de ensino-aprendizagem. Desde esta perspectiva, "[...] as DCN desafiam as formas cristalizadas tradicionais de ensino-aprendizagem, visando à formação de profissionais-cidadãos empenhados na produção de cuidados em resposta às demandas sociais. Destarte, utilizar metodologias ativas e inovadoras significa investir em uma formação que se aproxime tanto quanto possível da vida real". 5, p. 416

Nessa concepção, o papel do professor passa a ser de mediador/facilitador, apoiando e estimulando a construção do conhecimento. ${ }^{6}$ Os docentes devem ter como foco o estímulo e a potencialização do pensamento crítico e reflexivo dos estudantes sobre os problemas da vida real que Ihes são apresentados, instigando a participação ativa, tanto no âmbito da (re)construção e aprofundamento como da ampliação dos saberes. 3,5,6

Nesse contexto, as metodologias ativas permitem a incorporação dos conhecimentos de forma significativa e duradoura. Os discentes participam do processo de construção de sua aprendizagem, sentindo-se parte daquilo que estão aprendendo, transpassando, assim, a mera reprodução dos conteúdos da metodologia tradicional na qual os estudantes são receptáculos passivos. ${ }^{7}$ A perspectiva é de uma construção dialógica, criativa e transformadora, em contraposição à relação verticalizada, bancária e estática. ${ }^{7,8}$ Nesse processo, no qual o estudante atua criticamente, a relação entre docentes e discentes passa a ser de parceria, observando o que ocorre em seu cotidiano, transformando o seu discurso e empoderando-se..$^{2,3,5,6}$ 
Nessa perspectiva, de entre os recursos inovadores do processo de ensinoaprendizagem e avaliação, destaca-se o portfólio, como instrumento/estratégia de estimulação do pensamento. Especificamente no caso dos estudantes de Enfermagem, da Universidade Federal de Viçosa (UFV), na disciplina de Políticas de Saúde, utiliza-se o portfólio reflexivo com o propósito de promover o aprendizado sobre as políticas de saúde, destacando-se a política nacional de saúde no Brasil, o SUS, de forma crítica, reflexiva, dialética e dialógica, visando ao estímulo do trabalho em equipe por meio de um processo de construção coletiva do portfólio.

Nessa acepção, é notável destacar que, empregando a inovadora metodologia, seria possível transformar os arquétipos clássicos de avaliação, ao estimular a integração entre aluno e professor, a interdisciplinaridade por meio da união de vários assuntos em um mesmo espaço, bem como facilitar os processos de auto e heteroavaliação, estimulando a curiosidade, a independência e a autoestima. ${ }^{9,10}$

No caso especifico da disciplina de Políticas de Saúde da UFV, o portfólio constituise em um instrumento de avaliação formativa, atuando "como um facilitador da reconstrução e reelaboração, por parte dos estudantes, de seu processo de aprendizagem". ${ }^{3,}$ p. 1855

Nesse contexto, a escolha desta temática se fundamenta na importância do estudo sobre o papel do portfólio no desenvolvimento da capacidade da crítica e reflexão dos estudantes de graduação, visando a uma formação consonante com a tendência contemporânea de formação de cidadãos com autonomia, criatividade e responsabilidade para atuar na busca de soluções de problemas no mundo da vida e do trabalho. $2,3,5,6$

Diante da relevância do tema, o presente estudo tem como objetivo central analisar a percepção dos estudantes do curso de Enfermagem de uma universidade pública sobre o processo de construção do portfólio reflexivo enquanto estratégia de ensino, aprendizagem e avaliação, na disciplina de Políticas de Saúde. 


\section{Metodologia}

ISSN 2179-6750

Trata-se de um estudo de natureza qualitativa cuja coleta de dados se deu durante o período de dezembro de 2014 a maio de 2015 com os estudantes que cursaram a disciplina de Políticas de Saúde.

A disciplina de Políticas de Saúde da UFV, Campus Viçosa, é oferecida semestralmente para estudantes da área da saúde, sendo trabalhadas as seguintes temáticas: os conceitos e conteúdos referentes ao campo das políticas públicas em saúde; os principais aspectos utilizados para análise dos sistemas sanitários; a formulação de políticas sociais, os desenhos de políticas e os modelos de serviços sanitários; determinantes estruturais, econômicos, políticos e sociais que repercutam sobre o processo saúde-doença e a prestação de serviços de saúde; os grandes tipos de serviços sanitários dos países e regiões do mundo; a política de saúde no Brasil e o desenho do Sistema Nacional de Saúde; Evolução história da saúde pública brasileira; o SUS. ${ }^{11}$

O portfólio, na disciplina de Políticas de Saúde, é construído coletivamente por equipes compostas por média de seis ou sete alunos. Seguindo os preceitos da avaliação formativa, o processo de avaliação dos portfólios é contínuo e longitudinal, sendo realizadas três avaliações durante o semestre.

O portfólio coletivo configura-se como importante estratégia para promover a competência do aprender a conviver e a trabalhar juntos, capacidade esta imprescindível para o trabalho em equipes interdisciplinares na área da saúde. Além de promover a competência do aprender a ser, tendo em vista que a aprendizagem se baseia no protagonismo dos estudantes e na comunicação dialógica entre os diferentes sujeitos. ${ }^{2}$

Participaram do estudo 32 estudantes de graduação em Enfermagem, de um total de 40 (oito não aceitaram participar) que cursaram a disciplina de Políticas de Saúde, no segundo semestre letivo no ano de 2014, e que concordaram em participar da pesquisa, após assinatura do Termo de Consentimento Livre e Esclarecido - TCLE.

A coleta de dados foi realizada utilizando duas técnicas: entrevistas e análise 
documental. As entrevistas foram realizadas por dois pesquisadores previamente treinados, orientados por um roteiro semiestruturado contendo vinte e duas questões. As entrevistas foram gravadas e transcritas pelos pesquisadores mantendo com fidedignidade a fala dos participantes.

As questões analisadas do roteiro utilizado foram: "Quais os pontos fortes (fortalezas) e fracos (fragilidades) do trabalho em equipe no processo de construção do portfólio? Cite algumas características relacionadas ao trabalho em grupo propiciado pelo processo de construção do portfólio coletivo; Para você existe diferença entre o portfólio e um para um trabalho tradicional feito em grupo? Qual a diferença entre o portfólio e a prova como métodos de avaliação?"

A análise documental é representada por documentos autênticos, designados fontes primárias; no caso deste estudo, esse corpus foi constituído pelos portfólios, no qual foram extraídos depoimentos dos estudantes que cursaram a disciplina de Políticas de Saúde. ${ }^{2}$ Assim, foram analisados um total de 7 portfólios construídos coletivamente no segundo semestre de 2014. Todas as construções, reflexões e documentos que compunham os portfólios estudados fizeram parte das análises realizadas neste estudo.

Para análise e interpretação dos dados das entrevistas e dos portfólios foi realizada a técnica de Análise do Conteúdo, que divide o percurso de análise nas seguintes etapas: leitura flutuante das entrevistas; seleção das unidades de significados; processo de

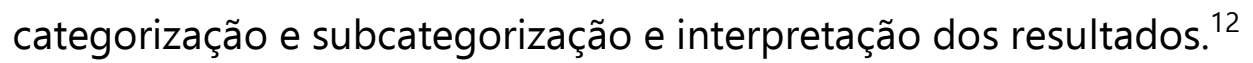

Para preservar o anonimato dos participantes, os mesmos foram identificados com a letra $E$ (estudantes) e atribuído numeração arábica, o qual indica a ordem em que foram realizadas as entrevistas (E1, E2, E3...). Os portfólios foram codificados pela letra P (portfólios) seguida da numeração arábica o qual foi feita aleatoriamente (P1, P2...).

Este estudo foi aprovado pelo Comitê de Ética em Pesquisa com Seres Humanos CEPH da UFV, Protocolo $n^{\circ}$ 135/ 2012/ CEPH/ 05-12-28, de acordo com a Resolução $n^{\circ}$ 466/2012 do Conselho Nacional de Saúde (CNS), que regulamenta as pesquisas envolvendo 
seres humanos. Foi solicitado consentimento livre e esclarecido dos estudantes para participarem do estudo, garantindo-se a confidencialidade das informações e o seu anonimato.

\section{Resultados}

A análise dos dados permitiu a emersão de duas categorias temáticas: "Processo de construção do portfólio: fatores facilitadores e dificultadores do trabalho em equipe" e "O portfólio como estratégia de ensino, aprendizagem e avaliação".

\section{Processo de construção do portfólio: fatores facilitadores e dificultadores do trabalho em equipe}

Nessa categoria temática, os principais achados estão ilustrados na Figura 1. Nesta destaca-se, por meio dos depoimentos dos estudantes, o portfólio como potente indutor e potencializador do trabalho em equipe, estimulando o exercício do respeito entre pares, da interação, da escuta qualificada e da alteridade.

Como fragilidade do processo de construção dos portfólios coletivos, os estudantes salientaram a dificuldade de gerirem o tempo para reuniões em horários compatíveis para os membros dos grupos, em virtude do grande acúmulo de tarefas comuns em currículos disciplinares e tradicionais. Como estratégia de amenização desta dificuldade mencionaram a utilização das redes sociais para encontros virtuais e discussões. 


\section{Fatores facilitadores e dificultadores do trabalho em Equipe}

\section{Facilitadores}

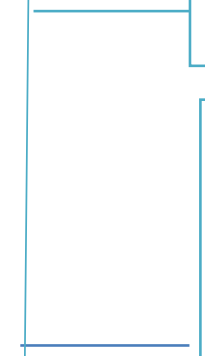$$
\begin{aligned}
& \text { "[...] aprende a lidar } \\
& \text { em equipe" (E11). }
\end{aligned}
$$

"Com o portfólio a gente aprende a lidar com a diversidade e juntos chegar a um consenso, aceitar a opinião dos outros; e isso é bom para carreira profissional" (E30).

\section{Integração/Interação:}

"a interação com os colegas e com o professor. A gente não conheceu somente quem estava no nosso grupo; quando o restante da sala falava a gente também aprendia a ouvir." (E12)

" a interação e saber trabalhar em equipe, já que daqui para frente, na prática, trabalhar em equipe é o que mais a gente vai precisar." (E13)

"Respeito à opinião do outro, compromisso com as atividades e com o horário $[\ldots] "$ (E32).

"[...] aprende a lidar com o outro, aprender a argumentar e discutir, a trabalhar$$
\text { profissional" (E30). }
$$

\section{Criatividade/ Criticidade/ reflexão:}

"[...] contribuiu pro pensamento crítico-reflexivo que antes eu não tinha. Eu passei a questionar as coisas, o que é super válido pra vida, pra carreira acadêmica, pra tudo" (E04).

"O portfólio instiga o desenvolvimento de habilidades como criatividade, proatividade e convivência" (P7).

"A construção do portfólio fez com que eu me visse uma pessoa mais críticareflexiva [...] aprendi a correlacionar o que é aprendido em sala de aula com o que é vivido por nós no cotidiano, tornando-me uma pessoa mais ativa na construção do meu próprio conhecimento" (P1).

\section{Dificultadores}

\section{Gestão do tempo:}

Figura 1. Representação esquemática dos fatores facilitadores e dificultadores do trabalho em equipe no processo de construção do portfólio reflexivo, segundo os depoimentos dos alunos. Fonte: Elaboração própria (2015).

"A disciplina no curso de enfermagem é aplicada num período muito puxado; com uma carga horaria muita alta" (E 20).

"Fragilidade em encontrar horários pra reuniões presenciais. Às vezes teve que ficar fazendo por whatsapp, por facebook. Como somos de anos diferentes não batiam os horários." (E10).

"Período com um grande número de créditos, o que nos impossibilitava dar uma maior dedicação a disciplina" (P5). 


\section{O portfólio como estratégia de ensino, aprendizagem e avaliação}

Os resultados inseridos nesta categoria expressam a percepção dos estudantes sobre o portfólio como estratégia de ensino, aprendizagem e avaliação, conforme demonstrado na Figura 2. Referente ao ensino, os estudantes evidenciaram o portfólio como estratégia que permite (re)significar e aprofundar o conteúdo da disciplina. Além de ser um mobilizador do trabalho em equipe, distinguindo-se do que ocorre em um trabalho tradicional, no qual há fragmentação das tarefas.

Observa-se ainda, por meio da Figura 2, que os estudantes identificam no portfólio um valioso recurso de consolidação do aprendizado, indo de encontro ao aprendizado propiciado pela metodologia tradicional, em que o estudante simplesmente memoriza a matéria de forma pontual - fazer uma prova, por exemplo. Além disso, estimula o pensamento crítico, reflexivo e criativo, estimulando e valorizando a participação do estudante, promovendo também a integração entre a teoria e a prática.

No que diz respeito à aprendizagem, mesmo sendo o portfólio bastante trabalhoso, este permitiu o crescimento enquanto estudante, cidadão e futuro profissional, ao estimular a reflexão e participação ativa nos acontecimentos do mundo real, principalmente aqueles ligados à saúde.

Enquanto método avaliativo, o portfólio é representado, sob a ótica dos estudantes, como uma maneira de avaliar o processo de aprendizagem, para além de um momento e conteúdo pontual, podendo (re)construir, refletir sobre o erro e corrigir rumos. A avaliação tem como foco o percurso do estudante, ou seja, a sua evolução, contribuindo para a sua formação. 


\section{O portfólio como estratégia de ensino, aprendizagem e avaliação}

"Às vezes o ensino é muito mecanizado. Você decora aquela matéria só para fazer a prova. Com o portfólio você reflete mais sobre aquilo que você está estudando" (E03).

Ensino

"O trabalho tradicional é muito fragmentado. Você pega e divide o trabalho entre os colegas. No final todo mundo fez alguma coisa, mas ninguém fez junto, ninguém lê o que o outro escreveu. No portfólio como você faz em grupo e é junto, tem que pensar junto. Tudo tinha a parte de todo mundo. "(E27)

"Foi essencial para a realização desse trabalho o feedback aluno-professor e entre grupo-grupo" (P2).

\begin{tabular}{|c|c|}
\hline Aprendizagem & $\begin{array}{l}\text { "Consigo perceber que ficou mais fácil estudar os conteúdos, de forma mais } \\
\text { realística, e não no método tradicional de memorização" (P1). }\end{array}$ \\
\hline
\end{tabular}

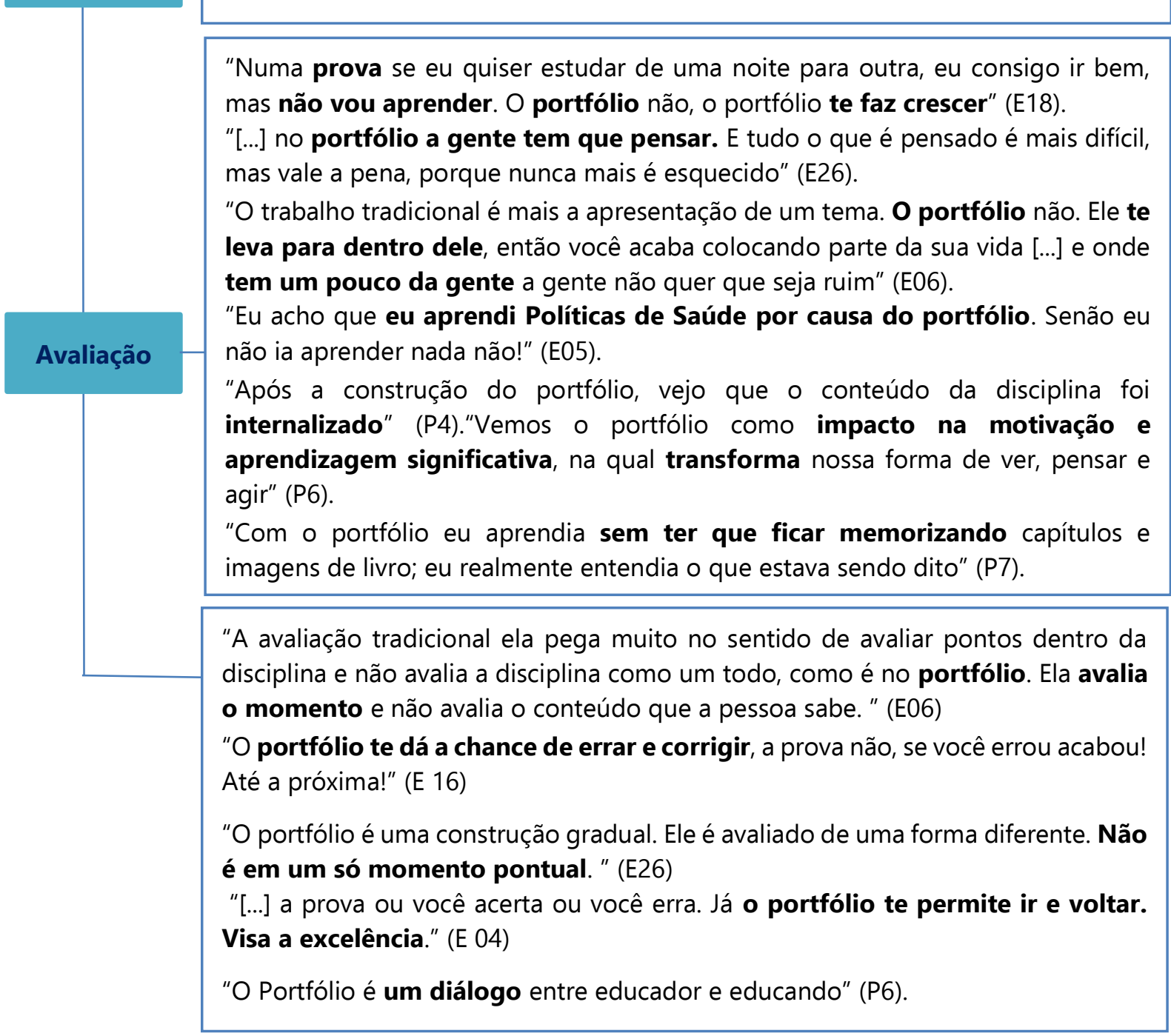

Figura 2. Representação gráfica do portfólio como instrumento de ensino, aprendizagem e avaliação.

Fonte: Elaboração própria (2015).

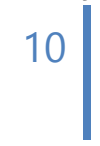


Enquanto método avaliativo, o portfólio é representado, sob a ótica dos estudantes, como uma maneira de avaliar o processo de aprendizagem, para além de um momento e conteúdo pontual, podendo (re)construir, refletir sobre o erro e corrigir rumos. A avaliação tem como foco o percurso do estudante, ou seja, a sua evolução, contribuindo para a sua formação.

Ademais, o portfólio apresenta-se como facilitador para a compreensão dos conteúdos de Políticas de Saúde pelos estudantes, estimulador do pensamento crítico e reflexivo, fomentador de agentes questionadores - não apenas dos conteúdos da disciplina em si, mas também no contexto de vida e de trabalho. Além de possibilitar aos estudantes uma visão mais ampliada sobre o SUS.

\section{Discussão}

Os achados deste estudo desvelaram que o portfólio se configurou como uma estratégia de ensino, aprendizagem e avaliação transformadora e potencializadora do trabalho em equipe, do pensamento crítico, reflexivo e criativo tão demandado no campo profissional e acadêmico. Tais achados vão ao encontro das recomendações propostas pelas DCN dos cursos da saúde do perfil do profissional enfermeiro. ${ }^{1,13}$

Segundo os relatos dos estudantes, o processo de construção do portfólio permitiu o exercício do trabalho em equipe, visando preparar o aluno para atuar no campo profissional da saúde, de modo a assegurar a assistência integral e a produção e promoção de cuidados em prol do usuário. Assim, desde a graduação, exercem uma prática comunicativa orientada para o entendimento mútuo, além de se tornarem comprometidos e científica e tecnicamente competentes para atuarem no processo de saúde-doençaadoecimento. 2,14 
A proposta do portfólio reflexivo enquanto estratégia de ensino, aprendizagem e avaliação na disciplina de Políticas de Saúde constituiu-se como metodologia ativa facilitadora do aprendizado, rompendo com a maneira mecânica de decorar e reproduzir os conteúdos, tendo em vista que os estudantes (re)pensam, analisam, refletem, questionam e criticam durante o processo de aquisição de conhecimento. ${ }^{15,16}$ Além disso, permitiu aos estudantes participarem ativamente de seu processo de ensino-aprendizagem, de modo a capacitá-los na condução das atividades desenvolvidas na universidade e no futuro ambiente de trabalho. ${ }^{13,17}$

Pode-se inferir, portanto, que o portfólio reflexivo foi de encontro ao processo de ensino-aprendizagem bancária no qual o professor é o detentor do conhecimento e o estudante mero reprodutor e receptáculo passivo. ${ }^{3} \mathrm{O}$ estudante passou a ser o centro da aprendizagem, de modo a participar de maneira interativa e dinâmica deste processo. ${ }^{17,18}$ Permitiu ainda, um posicionamento mais ativo, comprometido e criativo do estudante.

O portfólio configurou-se como uma estratégia de avaliação formativa que apoia o desenvolvimento do estudante fornecendo-Ihes um feedback para o aperfeiçoamento de suas habilidades em um processo longitudinal e estimulou uma constante autorreflexão. Nele a avaliação foi um processo contínuo, coparticipativo, no qual o erro foi percebido pelos estudantes como uma oportunidade.,19 "A postura, do professor e dos estudantes, foi dialógica, aberta, curiosa, indagadora e não apassivada, enquanto fala ou enquanto ouve". 7

Deste modo, o processo no qual o portfólio foi desenvolvido facilitou a compreensão do conteúdo, o interesse do estudante e o seu envolvimento. Constituiu-se como uma estratégia de avaliação construtiva e não punitiva. Tais achados confluem com o estudo, ${ }^{19}$, p. 777 no qual os estudantes apontam "o processo de aprendizagem propiciado pelo portfólio como profundo, e não superficial; como algo que fica na memória, que não se esquece".

Para Villas Boas, "o grande lance é este: o aluno não estuda para passar de ano, mas para aprender".20, p. 41 Assim, o significado atribuído por meio do portfólio no processo de ensino, aprendizagem e avaliação dos estudantes de enfermagem centrou-se no 
entendimento e na compreensão dos conteúdos, e não se focou na memorização para a prova, estimulando o aprendizado para a vida.

Destarte, a construção do portfólio como estratégia de ensino vem ao encontro dos pensamentos de Paulo Freire, ${ }^{7}$ o qual afirma que ensinar não é meramente transferir o conteúdo, mas viabilizar ao educando possibilidades para a produção e (re)construção do saber ensinado. Isso foi nítido no processo de avaliação dos estudantes sobre a construção do portfólio, pois o ponto central não é o achado, mas o processo de busca. Nesta direção, os estudantes enfatizam as competências adquiridas e desenvolvidas ao longo do semestre letivo, destacando-se a inquietude, a curiosidade, a postura indagadora, e não apassivada, a interação coparticipativa entre alunos-alunos e professor-alunos.

Por fim, pode-se destacar que o portfólio se constituiu em uma ferramenta eficaz e inovadora para que o processo de ensino-aprendizagem-avaliação fosse efetivo, prazeroso e transformador, viabilizando o que versou Paulo Freire. 7:28 "educadores e educandos criadores, instigadores, inquietos, rigorosamente curiosos e persistentes".

\section{Conclusão}

A percepção dos estudantes de Enfermagem revelada neste estudo sinalizou que a utilização do portfólio como estratégia de ensino, aprendizagem e avaliação na disciplina de Políticas de Saúde apresentou elementos positivos no que tange ao desenvolvimento de competências pelos estudantes, como o trabalho em equipe. Além disso, foi identificado que a gestão do tempo se apresentou como uma dificuldade dos estudantes, que buscaram trabalhar essa lacuna ao longo do semestre letivo. A avaliação formativa implementada contribuiu para o aperfeiçoamento dos estudantes em seu processo de formação profissional e cidadã.

Deste modo, investir em metodologias inovadoras é investir em possibilidades de aprendizagem que transcendem o ambiente universitário, e alcancem dimensões pessoais e 
profissionais. Em especial, no que se refere ao portfólio reflexivo, este estimulou a capacitação de futuros profissionais de saúde aptos para o trabalho em equipe, competência esta imprescindível para o cuidado integral e efetivo dos indivíduos, famílias e comunidades.

Ademais, a construção do portfólio permitiu o desenvolvimento de competências nas quais o estudante e futuro profissional enfermeiro necessitam desenvolver para a atuação em equipes interdisciplinares, como a escuta qualificada, a capacidade crítica, reflexiva e argumentativa, o respeito entre pares, a interação, a alteridade e o conhecimento sobre o SUS. Assim, o portfólio mostrou-se como um grande potencial para ampliar, (re)pensar e inovar o ensino de graduação.

\section{Apoio}

Projeto Financiado pela Coordenação de Aperfeiçoamento de Pessoal de Nível Superior (CAPES), Brasil, entidade do governo brasileiro voltada para a formação de recursos humanos. Processo n. 23038.009788/2010-78; AUX-PE-Pró-Ensino na Saúde, 2034/2010.

\section{Referências}

1. Ministério da Educação (BR). Conselho Nacional de Educação. Câmara de Educação Superior. Resolução CNE/CES n³ 3/2001, de 7 de novembro de 2001. Institui Diretrizes Curriculares Nacionais do Curso de Graduação em Enfermagem. Diário Oficial da União, Brasília (DF): Diário Oficial da União; 9 nov 2001 [acesso em 5 set 2016]. Disponível em: http://www.cofen.gov.br/wpcontent/uploads/2012/03/resolucao_CNE_CES_3_2001Diretrizes_Nacionais_Curso_Gradu acao_Enfermagem.pdf

2. Cotta RMM, Costa GD, Mendonça ET. Portfólio reflexivo: uma proposta de ensino e aprendizagem orientada por competências. Cienc Saude Colet. 2013;18(6):1847-56. http://dx.doi.org/10.1590/S1413-81232013000600035.

3. Cotta RMM, Silva LS, Lopes LL, Gomes KO, Cotta FM, Lugarinho R, et al. Construção de portfólios coletivos em currículos tradicionais: uma proposta inovadora de ensinoaprendizagem. Cienc Saude Colet. 2012;17(3):787-96. http://dx.doi.org/10.1590/S141381232012000300026. 
4. Rossi NF, Fortuna CM, Matumoto S, Marciano FM, Silva JB, Silva JS. As narrativas de estudantes de enfermagem nos portfólios do Estágio Curricular Supervisionado. Rev Eletron Enferm. 2014;16(3):566-74. https://doi.org/10.5216/ree.v16i3.25691.

5. Cotta RMM, Mendonça ET, Costa GD. Portfólios reflexivos: construindo competências para o trabalho no Sistema Único de Saúde. Rev Panam Salud Publica. 2011;30(5):41521.

6. Cotta RMM, Costa GD, Mendonça ET, Cotta F M, Mitre SM, Cotta RM. Portfólios críticosreflexivos e a construção do conhecimento significativo na formação de profissionais de saúde. Rev CIDUI [Internet]. 2012 [citado em 5 maio 2015];(1):1-24. Disponível em: http://www.cidui.org/revistacidui/index.php/cidui/article/view/205/194

7. Freire P. Pedagogia da autonomia: saberes necessários à prática educativa. 45a. ed. Rio de Janeiro: Paz e terra; 2013.

8. Marin MJS, Lima EFG, Paviotti AB, Matsuyama DT, Silva LKD, Gonzalez C, et al. Aspectos das fortalezas e fragilidades no uso das metodologias ativas de aprendizagem. Rev Bras Educ Med. 2010;34(1):13-20. http://dx.doi.org/10.1590/S0100-55022010000100003.

9. Otrenti E, Jodas DA, Silva LG, Aguilera TKC, Vannuchi MTO. Portfólio reflexivo como método de avaliação na residência de gerência de serviços de enfermagem. Semina Cienc Biol Saude. 2011;32(1):41-6. http://dx.doi.org/10.5433/1679-0367.2011v32n1p41.

10. Alves ED, Ribeiro LSN, Guimarães DCSM, Costa CMA, Peixoto HM, Martins EF, et al. Moodle-fólio para o ensino em saúde e enfermagem: avaliação do processo educacional. Rev Eletron Enferm. 2012;14(3):473-82. https://doi.org/10.5216/ree.v14i3.19109.

11. Universidade Federal de Viçosa. Pró-Reitoria de Ensino. Campus Viçosa. Catálogo de graduação 2014. Viçosa: UFV; 2014.

12. Bardin L. Análise de conteúdo. Lisboa: Edições 70; 2011.

13. Cotta RMMC, Silva LS, Costa GD, Mendonça ET, Cotta FM, Campos AAO, et al. Portfólios coletivos reflexivos como método de ensino e aprendizagem: potencializando a autonomia, a criatividade e o trabalho em equipe. Rev. CIDUI [Internet]. 2014 [citado em 11 abr 2015]; (2):1-11. Disponível em:

http://www.cidui.org/revistacidui/index.php/cidui/article/view/647 
14. Maciel JAC, Norte AEO, Feitosa SG, Moreira TP, Farias MR, Teixeira AKM. Percepção dos acadêmicos do curso de odontologia sobre o uso do portfólio como método avaliativo. Rev Eletron Gest Saude [Internet]. 2014 [citado em 11 abr 2015];5(2):279-89. Disponível em: http://gestaoesaude.unb.br/index.php/gestaoesaude/article/view/737/pdf.

15. Silva LS, Cotta RMM, Costa GD, Campos AAO, Cotta RM, Silva LS, et al. Formação de profissionais críticos-reflexivos: o potencial das metodologias ativas de ensino aprendizagem e avaliação na aprendizagem significativa. Rev CIDUI [Internet]. 2014 [citado em 16 jul 2015];(2):1-16. Disponível em: http://www.cidui.org/revistacidui/index.php/cidui/article/view/541/522.

16. Vaz DR, Prado C. Prática pedagógica reflexiva de licenciados de enfermagem: o portfólio como instrumento. Rev Esc Enferm USP. 2014;48(6):1103-10. https://doi.org/10.1590/S0080-623420140000700019.

17. Cotta RMM, Costa GD, Mendonça ET. Portfólios crítico-reflexivos: uma proposta pedagógica centrada nas competências cognitivas e metacognitivas. Interface Comun Saude Educ. 2015;19(54):573-88. http://dx.doi.org/10.1590/1807-57622014.0399.

18. Tompkins $M$, Paquette-Frenette $D$. Learning portfolio models in health regulatory colleges of Ontario, Canada. J Contin Educ Health Prof. 2010;30(1):57-64. https://doi.org/10.1002/chp.20057.

19. Costa GD, Cotta RMM. "Learning-by-doing": social representations of healthcare students regarding reflective portfolio as a teaching, learning and assessment method. Interface. 2014;18(51):771-84. http://dx.doi.org/10.1590/1807-57622014.0150.

20. Villas Boas BMF. Portfólio, avaliação e trabalho pedagógico. Campinas: Papirus; 2005. 
Ana Paula da Silva Lemos | ORCiD: 0000-0001-9676-4408

Graduação em Enfermagem pela Universidade Federal de Viçosa - UFV. Especialista em Enfermagem Obstétrica, na modalidade residência, pelo Hospital Sofia Feldman.

Rosângela Minardi Mitre Cotta | ORCiD: 0000-0001-5331-9734

Professora Titular da Universidade Federal de Viçosa - UFV. Doutora em Saúde Pública pela Universidad de Valencia, Espanha. Coordenadora do Programa de Inovação em Docência Universitária - PRODUS da UFV. Coordenadora do Laboratório de Estudos em Planejamento e Gestão em Sade - LABPANGEST da UFV.

Glauce Dias da Costa | ORCiD: 0000-0002-2630-194X

Professora Adjunto (Dr) da Universidade Federal de Viçosa (UFV), Departamento de Nutrição e Saúde - DNS. Doutorado em Ciências da Nutrição pela Universidade Federal de Viçosa.

Erica Toledo de Mendonça | ORCiD: 0000-0002-3014-1504

Professora Adjunto II do Departamento de Medicina e Enfermagem da Universidade Federal de Viçosa - UFV. Doutorado pelo Programa de Pós-graduação em Ciência da Nutrição da Universidade Federal de Viçosa.

Emily de Souza Ferreira | ORCiD: 0000-0003-4451-0611

Graduação em Nutrição pela Universidade Federal de Viçosa - UFV. Mestranda em Ciências da Nutrição pela UFV. 